\title{
Mobilization of Reinforcement Forces in Fiber-Reinforced Soil
}

\author{
Chunling Li, M.ASCE${ }^{1}$; and Jorge G. Zornberg, M.ASCE ${ }^{2}$
}

\begin{abstract}
Fiber reinforcement represents a promising alternative in projects involving localized repair of slopes and reinforcement of thin soil veneers, where planar reinforcement (e.g., with geotextiles and geogrids) is difficult to implement. Current design methodologies allow quantification of the shear strength of fiber-soil composites in terms of the parameters that independently characterize the soil matrix and fibers. The shear strength of fiber-reinforced soil is considered to have two components, including the shear strength of the soil matrix and the tension mobilized within the fibers. Triaxial compression tests and fiber pullout tests were conducted to evaluate how the fiber tension is mobilized for varying shear strain levels. The results of this evaluation provide insights into whether the shear strength of fiber-reinforced soil is governed by the peak or residual shear strength of unreinforced soil. A revision to existing design methodology is proposed in which the individual contribution of fibers and soil matrix is quantified based on the strain level. The appropriateness of using the peak or residual shear strength of the unreinforced soil for predicting the equivalent shear strength of fiber-soil composites is discussed based on strain compatibility considerations. DOI: 10.1061/(ASCE)GT.1943-5606.0000745. (C) 2013 American Society of Civil Engineers.
\end{abstract}

CE Database subject headings: Fibers; Shear strength; Soil stress; Stress strain relations.

Author keywords: Fiber reinforcement; Peak and residual shear strength; Soil; Stress-strain behavior.

\section{Introduction}

Traditional methods of soil reinforcement involve the use of continuous planar inclusions (e.g., metallic strips, geogrids, and geotextiles) within earth structures, which provide tensile resistance to the soil in a particular direction. While the contribution by tensile stresses may be significant, potential planes of weakness may be introduced because the shear resistance of the soil-reinforcement interface is usually below that of the soils alone.

Short discrete fibers, if mixed uniformly within the soil mass, can provide an isotropic increase in shear strength to the soil composite without introducing planes of weakness. Fiber reinforcement has been found to be a promising solution for repair of localized slope failures and for reinforcement of thin soil veneers (Zornberg et al. 2001), in which implementation of planar reinforcement alternatives is difficult because of geometric constraints.

In the design of fiber-reinforced soil structures, the fiber-soil mixture has often been considered as a composite with an equivalent shear strength represented by equivalent cohesion and friction angle values. A discrete framework proposed by Zornberg (2002) provides a method to predict the equivalent shear strength of fiber-reinforced soil based on the independent properties of fibers and soil (e.g., fiber content, fiber aspect ratio, and shear strength of unreinforced soil). In this framework, fibers are assumed to contribute to the shear strength increase by mobilizing tensile stress along the plane of shear. Therefore, the equivalent shear strength of fiber-reinforced soil has the following two

\footnotetext{
${ }^{1}$ Engineer, Geosyntec Consultants, 10220 Old Columbia Rd., Suite A, Columbia, MD 21046 (corresponding author). E-mail: cli@geosyntec.com

${ }^{2}$ Fluor Centennial Professor, Dept. of Architectural and Environmental Engineering, Univ. of Texas at Austin, 1 University Station C1792, Austin, TX 78712. E-mail: Zornberg@mail.utexas.edu

Note. This manuscript was submitted on September 21, 2011; approved on April 11, 2012; published online on April 13, 2012. Discussion period open until June 1, 2013; separate discussions must be submitted for individual papers. This paper is part of the Journal of Geotechnical and Geoenvironmental Engineering, Vol. 139, No. 1, January 1, 2013. CASCE, ISSN 1090-0241/2013/1-107-115/\$25.00.
}

components: the shear strength of the soil matrix and the fiber-induced tension.

A testing program including triaxial compression tests and fiber pullout tests was implemented as part of this study to evaluate the mobilization of the fiber-induced tension as a function of the shear strain level of the fiber-reinforced soil. Based on the test results, this paper discusses the appropriateness of using the peak or residual shear strength of the unreinforced soil in the discrete framework based on strain compatibility considerations. A brief overview of the discrete framework is first presented. The effect of fiber reinforcement on the stress-strain behavior obtained from a triaxial compression testing program is evaluated subsequently, with particular emphasis on the behavior of fiber-reinforced specimens with various densities. Finally, suggestions regarding the use of the peak or residual strength of unreinforced soil in the discrete framework are provided.

\section{Overview of the Discrete Framework}

Fiber reinforcement increases the shear resistance of fiber-reinforced soil by mobilizing tensile stress within fibers. Accordingly, the equivalent shear strength, $S_{\text {eq }}$, of a fiber-reinforced specimen has been defined in a discrete framework as a function of the fiber-induced distributed tension, $t$, and the shear strength of the unreinforced soil, $S$, as follows (Zornberg 2002):

$$
S_{\mathrm{eq}}=S+\alpha \cdot t=c+\sigma_{n} \tan \phi+\alpha \cdot t
$$

where $\alpha=$ empirical coefficient that accounts for the orientation of the fibers, $t=$ fiber-induced tension defined as the tensile force per unit area induced in a soil mass by randomly distributed fibers, and $c$ and $\phi=$ shear strength parameters of the unreinforced soil.

The discrete framework derives the expression of $t$ based on the governing failure mode. Under low confining stresses, when failure is governed by the pullout of the fibers, the fiber-induced distributed tension, $t_{p}$, can be estimated as

$$
t_{p}=\chi \cdot \eta \cdot\left(c_{i, c} \cdot c+c_{i, \phi} \cdot \tan \phi \cdot \sigma_{n, \text { ave }}\right)
$$


where $\eta=$ aspect ratio, defined as the ratio of the fiber length over the equivalent diameter of individual fibers; $\chi=$ volumetric fiber content, defined as the ratio of the fiber volume over the volume of the fiber-soil composite; and $\sigma_{n \text {,ave }}=$ average normal stress acting on the fibers. In the subsequent discussion, gravimetric fiber content $\chi_{w}$, defined as the ratio of the weight of the fiber over the dry weight of the soil, is also used in place of the volumetric fiber content because the gravimetric fiber content is easier to measure. The interaction coefficients, $c_{i, c}$ and $c_{i, \phi}$, commonly used in soil reinforcement literature for continuous planar reinforcement, have also been adopted to relate the interface shear strength to the shear strength of the soil. The interaction coefficients are defined as

$$
\begin{gathered}
c_{i, c}=\frac{a}{c} \\
c_{i, \phi}=\frac{\tan \delta}{\tan \phi}
\end{gathered}
$$

where $a=$ adhesive component of the interface shear strength between the soil and the polymeric fiber, and $\tan \delta=$ frictional component. When failure is governed by the yielding of the fibers, the distributed tension, $t_{t}$, is determined from the tensile strength of the fiber as follows:

$$
t_{t}=\chi \cdot \sigma_{f, \mathrm{ult}}
$$

where $\sigma_{f \text {, ult }}=$ ultimate tensile strength of the individual fibers.

Accordingly, the following expressions have been derived to define the equivalent shear strength when failure is governed by fiber pullout:

$$
\begin{aligned}
S_{\mathrm{eq}, p} & =c_{\mathrm{eq}, p}+(\tan \phi)_{\mathrm{eq}, p} \cdot \sigma_{n} \\
c_{\mathrm{eq}, p} & =\left(1+\alpha \cdot \eta \cdot \chi \cdot c_{i, c}\right) \cdot c \\
(\tan \phi)_{\mathrm{eq}, p} & =\left(1+\alpha \cdot \eta \cdot \chi \cdot c_{i, \phi}\right) \cdot \tan \phi
\end{aligned}
$$

Equivalently, the following expressions have been obtained to define the equivalent shear strength when failure is governed by the tensile breakage of the fibers:

$$
\begin{gathered}
S_{\mathrm{eq}, t}=c_{\mathrm{eq}, t}+(\tan \phi)_{\mathrm{eq}, t} \cdot \sigma_{n} \\
c_{\mathrm{eq}, t}=c+\alpha \cdot \chi \cdot \sigma_{f, \mathrm{ult}} \\
(\tan \phi)_{\mathrm{eq}, t}=\tan \phi
\end{gathered}
$$

Eqs. (9)-(11) yield a bilinear shear strength envelope, which is shown in Fig. 1.

\section{Experimental Testing Program}

\section{Triaxial Compression Tests of Fiber-Soil Composites}

A laboratory testing program was implemented to validate the discrete framework and to study the strain compatibility associated with the progressive mobilization of fiber-induced tension. The laboratory testing program conducted in this study involves two series of triaxial compression tests (see Table 1), conducted in general accordance with ASTM D4767 (ASTM 1995). The fibers used in the

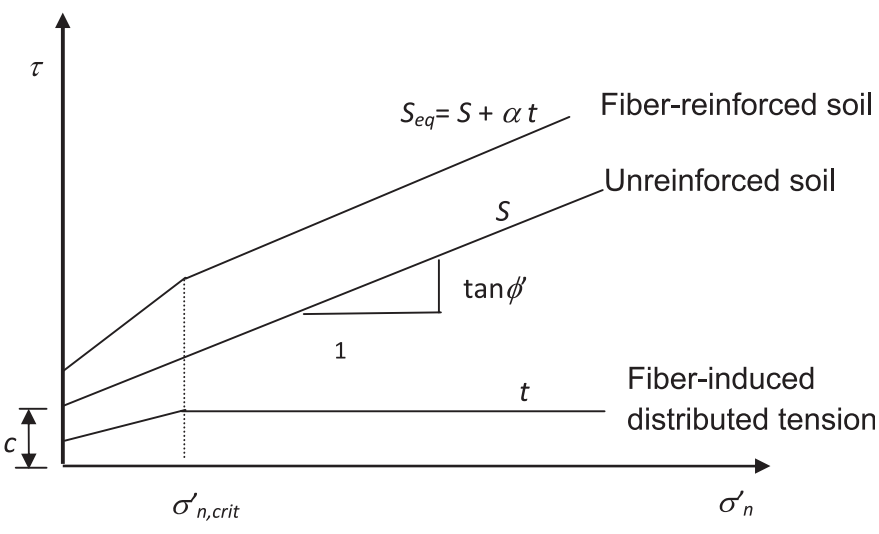

Fig. 1. Representation of the equivalent shear strength according to the discrete approach

testing program are commercially available polypropylene fibers with lengths of 25 and $50 \mathrm{~mm}$.

Test Series 1 was designed to quantify the effect of the fiber aspect ratio and fiber content on the shear strength behavior of fiberreinforced soil. The selected fibers had linear densities of 360 and 1,000 denier (where a denier is defined as the mass in grams per $9,000 \mathrm{~m}$ of fiber) and fiber lengths of 25 and $50 \mathrm{~mm}$. The specimens were prepared using two different gravimetric fiber contents $(0.2$ and $0.4 \%)$. Both fibrillated and regular tape fibers were used. The triaxial specimens had a diameter of $71 \mathrm{~mm}$ and a height of $142 \mathrm{~mm}$, and were tested using confining pressures of 35,70 , and $140 \mathrm{kPa}$. The tests were conducted under consolidated drained (CD) conditions.

Test Series 2 was designed primarily to compare the behavior of fiber-reinforced soil compacted to two different soil densities (relative densities of 48 and 65\%). Specifically, specimens of Soil 2 were prepared using two relative densities and placed at gravimetric fiber contents of $0.1,0.2,0.3$, and $0.4 \%$. The reinforcements were 50-mm-long, 3,620-denier fibrillated fibers. Large-scale specimens with a diameter of $152 \mathrm{~mm}$ and a height of $304 \mathrm{~mm}$ were used in this test series. The specimens were tested under dry condition using confining pressures of 60,115 , and $210 \mathrm{kPa}$, with air allowed to flow freely in and out of the specimen (i.e., volume changes were allowed).

The desired fiber amount was determined considering the dry weight of the soil and the desired gravimetric fiber content when preparing each specimen. The fibers and soils were uniformly hand mixed. Visual inspection showed that good uniformity was achieved. The mixture was then transferred to a mold and compacted to the desired soil density using a vibrating table.

Soil 1, used in Test Series 1, classified as poorly graded sand (SP), according to the Unified Soil Classification System (USCS). The percentage of fines passing through a No. 200 sieve was $1.4 \%$. Triaxial compression tests were conducted on the unreinforced soils, leading to a shear strength envelope defined by cohesion of $6.1 \mathrm{kPa}$ and a friction angle of $34.3^{\circ}$.

Soil 2, used in Test Series 2, was clean uniformly graded sand that also classified as SP according to the USCS. The sand particles were rounded to subrounded, consisting of mainly quartz and a small amount of feldspars and other minerals. The average diameter, $D_{50}$, was $0.4 \mathrm{~mm}$ and the specific gravity was 2.655 . Based on the gradation curve, the coefficient of uniformity was 3 and the coefficient of curvature was approximately 1.1. The maximum and minimum void ratios were 0.56 and 0.78 , respectively. Triaxial CD tests were conducted on unreinforced Soil 2 specimens prepared using two relative densities (48 and 65\%). The test results showed 


\begin{tabular}{|c|c|c|c|c|c|c|c|c|}
\hline \multirow[b]{2}{*}{ Series } & \multirow[b]{2}{*}{ Type of test } & \multicolumn{3}{|c|}{ Soil } & \multicolumn{4}{|c|}{ Fibers } \\
\hline & & Soils & $\begin{array}{c}\text { USCS } \\
\text { classification }\end{array}$ & $\begin{array}{c}\text { Relative density, } \\
D_{r}(\%)\end{array}$ & $\begin{array}{l}\text { Liner density } \\
\text { (denier) }\end{array}$ & $\begin{array}{l}\text { Length, } \\
l_{f}(\mathrm{~mm})\end{array}$ & $\begin{array}{l}\text { Fiber content, } \\
\qquad \chi_{w}(\%)\end{array}$ & Comment \\
\hline 1 & $\begin{array}{l}\text { Triaxial compression, } \\
\text { CD }\end{array}$ & Soil 1 & SP & 55 & 360 and 1,000 & 25 and 50 & 0.2 and 0.4 & $\begin{array}{l}\text { Both fibrillated fiber and } \\
\text { tape fiber were used }\end{array}$ \\
\hline 2 & $\begin{array}{l}\text { Triaxial compression, } \\
\text { dry specimen, } C D\end{array}$ & Soil 2 & SP & 48 and 65 & 3,620 & 50 & $\begin{array}{l}0.1,0.2,0.3 \text {, } \\
\text { and } 0.4\end{array}$ & Fibrillated fibers \\
\hline
\end{tabular}

that the strain at peak deviatoric stress decreased with the increasing relative density of soil. The stresses at a large strain level seemed to converge to the same value, although the specimens may not have been tested to strains that were large enough to achieve critical state. The mechanical properties of Soil 2 are shown in Table 2. The residual friction angle was approximately $31^{\circ}$.

The fibers used in the laboratory testing program are commercially available polypropylene fibers. A tensile testing program was implemented in accordance with ASTM D2256-97 (ASTM 1997) to quantify the tensile strength of the fibers (Zornberg 2002). The average tensile strength obtained from the tests was approximately 425,000 $\mathrm{kPa}$. The strain at failure ranged from approximately 10 to $20 \%$.

\section{Fiber Pullout Tests}

A specially designed pullout testing program using a single long fiber embedded in soil was conducted to quantify the interface shear strength between the fibers and soil, as required in the discrete framework. A large-scale pullout box was modified to perform the individual fiber pullout test. The test setup is shown in Fig. 2. The fiber used was a single, long polypropylene tape fiber that had not been cut in the manufacturing process. The pullout equipment had an upper box that sat on a bottom box of larger dimensions. A vertical hydraulic actuator was used to generate the normal load. The fiber was passed through two plastic tubes, placed at the bottom of the upper box, and used to control the effective length of fiber subjected to interface shear. The actual effective length of the fiber was $152 \mathrm{~mm}$ (6 in.), which was equal to the length of the upper box minus the length of the two plastic tubes, as shown in Fig. 2. The test setup is similar to a pull-through test, in which the length of fiber under interface friction remains constant during the test. The section of fiber subjected to interface shear was located in the center of upper box, which was under a uniformly distributed normal stress.

The pullout force was applied through horizontal hydraulic actuators. A load cell with a capacity of up to $50 \mathrm{lb}$ was installed to measure the pullout load. Two linear variable differential transformers (LVDTs) were used to measure the displacement in the pullout front and end. The front end of the fiber was attached to a metal wire, which can be considered as inextensible. Therefore, the measurements made using LVDT 1 can be assumed to correspond to the frontal pullout displacement. The displacement of the pullout end was measured by LVDT 2.

The soil used in the fiber pullout test was the same as that used in Series 2 of the triaxial compression tests. The soils were compacted to the target density using pluviation techniques, which involve raining the sand from a fixed height through a specially designed funnel. The target soil densities, $D_{r}$, were 48 and $65 \%$.

\section{Interface Shear Strength between Fiber and Soil}

The test results obtained from the pullout test were used to determine the interface shear strength between the fiber and soil. The pullout
Table 2. Mechanical Properties of Soil 2

\begin{tabular}{lcc}
\hline Parameter & \multicolumn{2}{c}{ Value } \\
\hline Relative density, $D_{r}(\%)$ & 48 & 65 \\
Dry unit weight $\left(\mathrm{kN} / \mathrm{m}^{3}\right)$ & 15.54 & 15.91 \\
Friction angle, $\phi^{\prime}\left(^{\circ}\right)$ & 31.6 & 35.2 \\
Cohesion, $c^{\prime}(\mathrm{kPa})$ & 0 & 0 \\
\hline
\end{tabular}

force versus pullout displacement curve obtained for the tests conducted using a relative soil density of $65 \%$ is shown in Fig. 3. The interface shear strengths were obtained by curve fitting the pullout force versus the displacement relationship using a load transfer model (Juran and Chen 1988). For characterization of the fibers' surface area, they were assumed to have a circular cross section with the same area. This assumption is a result of the difficulty in defining the surface area of fiber that is effectively in contact with the soil (especially for fibrillated fibers). The coefficient of interaction obtained, as shown in Table 3, showed a decreasing trend with increasing confining pressure. This observation is consistent with the fiber pull-through test results reported by Michalowski and Cermak (2003). For confining pressures between 0 and $210 \mathrm{kPa}$, which is typical of triaxial tests, a coefficient of interaction of 0.8 and an equivalent diameter calculated using a circular cross-sectional assumption is considered adequate for determining the fiber pullout resistance in the discrete framework.

\section{Validation of the Discrete Framework}

The discrete framework was validated using the results obtained from the triaxial tests. Specifically, the effect of the fiber content and aspect ratio was examined. Eqs. (6)-(8) were used to predict the equivalent shear strength of the fiber-reinforced specimens. An interaction coefficient $\left(c_{i, \phi}\right)$ of 0.8 was used in the analyses based on the interface shear strength obtained from the fiber pullout test results (interaction coefficient $c_{i, c}$ is not used for granular soil with zero cohesion). Zornberg (2002) recommended using a factor $\alpha$ of 1.0 for randomly distributed fibers. The use of these parameters has yielded reasonably good prediction of shear strength for fiberreinforced sand or silt obtained from triaxial compression tests $(\mathrm{Li}$ and Zornberg 2003; Zornberg and Li 2003). However, a preferential fiber orientation (typically, horizontal) may still exist for randomly mixed fibers as a result of the effect of self-weight. A value of $\alpha$ that is lower than 1.0 corresponds to the case in which the orientation of the shear plane is close to the preferential orientation of the fibers. Sadek et al. (2010) reported that a value of $\alpha$ of 0.4 provided good prediction for the shear strength results obtained from the direct shear tests, in which the shear plane coincided with the preferential orientation of the fibers. However, because shear planes in triaxial compression tests intersect the preferential fiber orientation with a relatively large angle, a value of $\alpha$ equal to 1.0 was selected in this study, which is consistent with the original recommendation. 


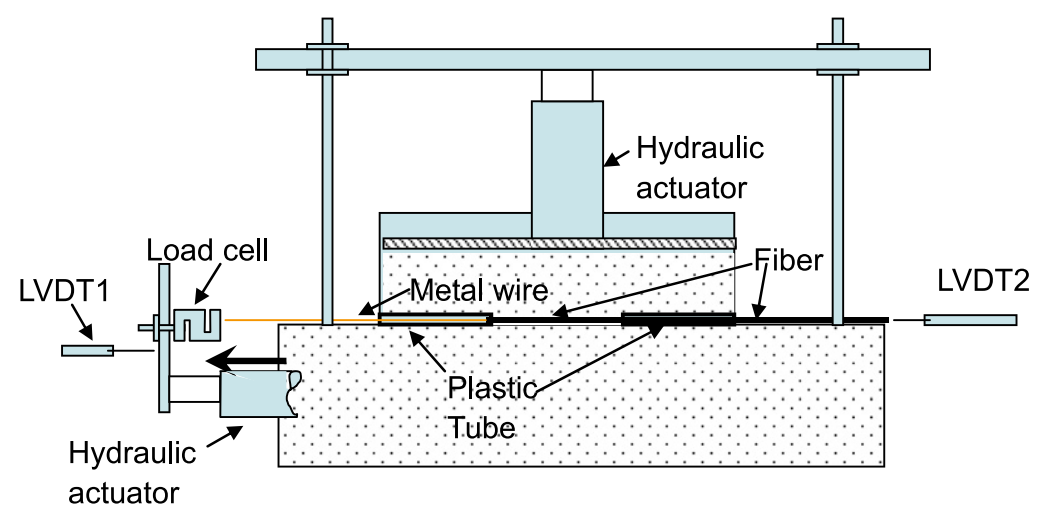

Fig. 2. Setup of the fiber pullout test

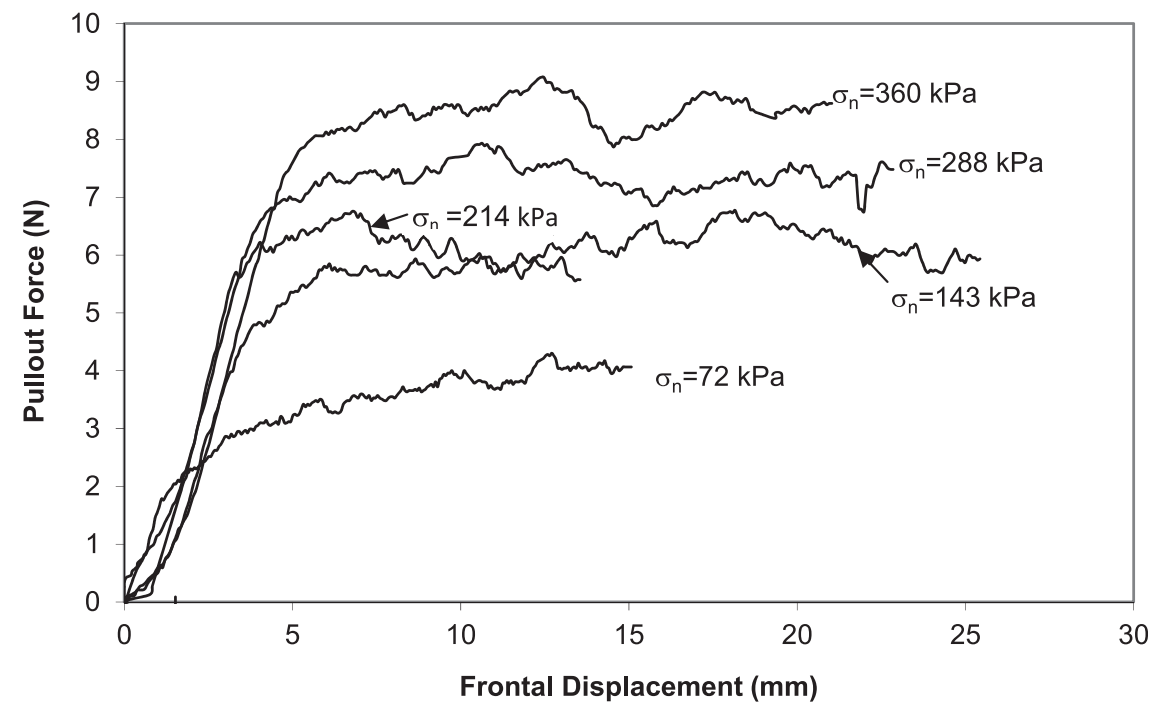

Fig. 3. Pullout force versus displacement curve (Soil 2, $D_{r}=65 \%$ )

Table 3. Parameter $c_{i, \phi}$ Determined from Fiber Pullout Tests

\begin{tabular}{lccc}
\hline $\begin{array}{l}\text { Normal stress, } \\
\sigma_{n}(\mathrm{kPa})\end{array}$ & $\begin{array}{c}\text { Series P-1, } \\
c_{i, \phi}\left(D_{r}=48 \%\right)\end{array}$ & $\begin{array}{c}\text { Series P-2, } \\
c_{i, \phi}\left(D_{r}=65 \%\right)\end{array}$ & $\begin{array}{c}\text { Series P-3, } \\
c_{i, \phi}\left(D_{r}=65 \%\right)\end{array}$ \\
\hline 71.5 & 0.87 & 1.35 & 0.91 \\
143 & 0.72 & 0.86 & 0.83 \\
214 & 0.70 & 0.57 & 0.56 \\
286 & & & 0.49 \\
358 & & & 0.45 \\
\hline
\end{tabular}

Inspection of Eq. (8) indicates that the shear strength increase as a result of fiber reinforcement is proportional to both fiber content $\chi$ and fiber aspect ratio $\eta$. Consequently, fiber-reinforced specimens reinforced using the same $(\chi \cdot \eta)$ values will have the same shear strength increase. This relationship is validated with the results presented in Figs. 4 and 5.

For granular soils without cohesion, the shear strength increase as a result of fiber reinforcement can be represented by a normalized friction angle $\tan \phi_{\text {eq }} / \tan \phi$. Considering that $\phi_{\text {eq }}$ and $\phi$ correspond to the peak friction angle values, the relationship between the normalized friction angle and the product of the fiber content and fiber aspect ratio can be obtained from Eq. (8) as follows:

$$
(\tan \phi)_{\mathrm{eq}, p} / \tan \phi=1+\alpha \cdot c_{i, \phi} \cdot \chi \cdot \eta
$$

Eq. (12) shows that the normalized friction angle increases linearly with increasing fiber content for soils reinforced using fibers with a given aspect ratio. Fig. 6 shows the normalized shear strength as a function of fiber-reinforced soils with 48 and $65 \%$ relative soildensities in Test Series 2. The trend lines obtained using linear regression are also shown in Fig. 6. The linear relationship represented by Eq. (12) is validated with the results presented in Fig. 6 for fiber-reinforced soil specimens prepared at a relative density of $48 \%$ (Test Series 2). For fiber-reinforced soil specimens prepared at a relative density of $65 \%$, the rate of increase of the normalized friction angle with fiber content is smaller than the rate of increase for fiber-reinforced soil specimens prepared at a relative density of $48 \%$. However, Eq. (12) shows that the slope of the normalized friction angle versus fiber content curve depends only on $\alpha, \chi$, and $\eta$.

The results presented in Figs. 4 and 5 were obtained using medium-dense soils, which do not show a significant difference between peak and residual strength values. However, the results presented in Fig. 6 show that for fiber-reinforced soil with high density, use of the peak friction angle of the unreinforced soil in the discrete framework may overestimate the equivalent shear strength of the fiber-reinforced soil. The appropriateness of using the peak or residual strength of unreinforced soil in the discrete framework is discussed in the subsequent sections. 


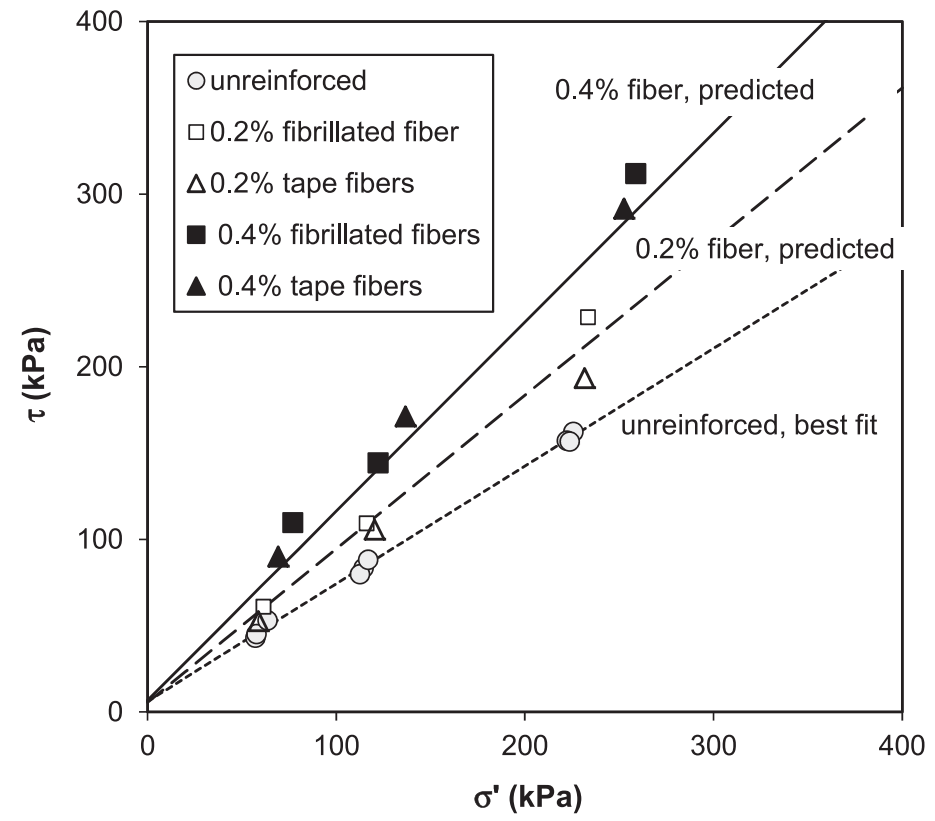

(a) 0.2 and $0.4 \%$, 25-mm long, 360-denier fibers

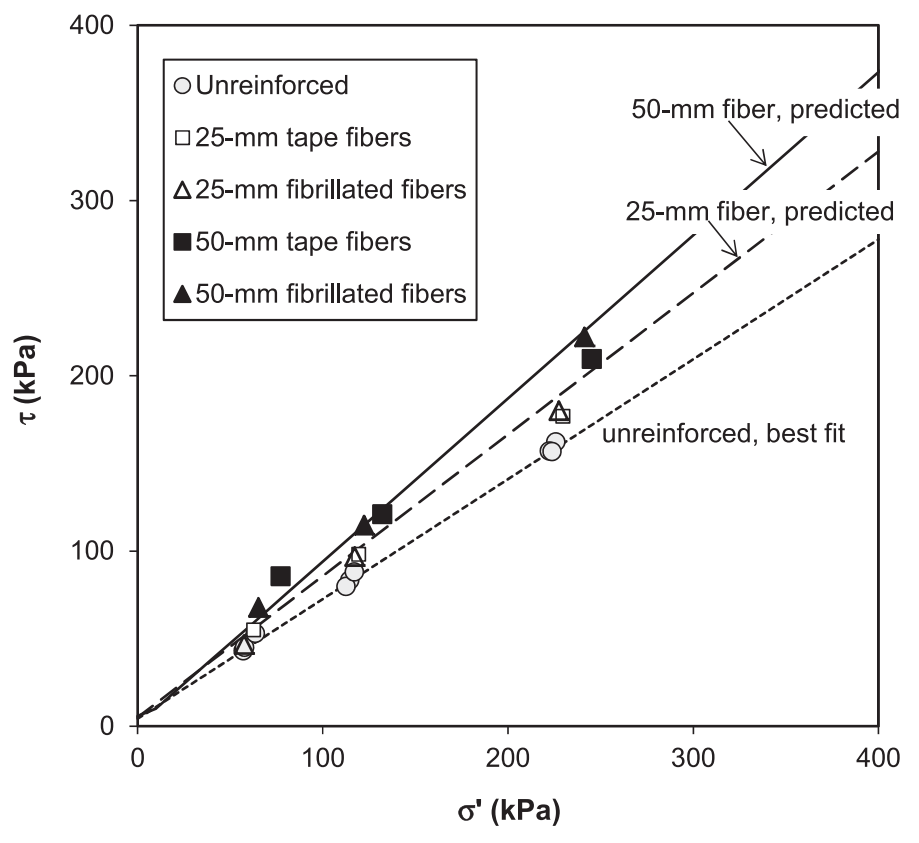

(b) $0.2 \%, 25$ - and $50-\mathrm{mm}$ long, 1000 -denier fibers

Fig. 4. Comparison of the predicted shear strength and experimental results (Soil 1): (a) 0.2 and 0.4\%, 25-mm long, 360-denier fibers; (b) 0.2\%, 25- and 50-mm long, 1,000-denier fibers

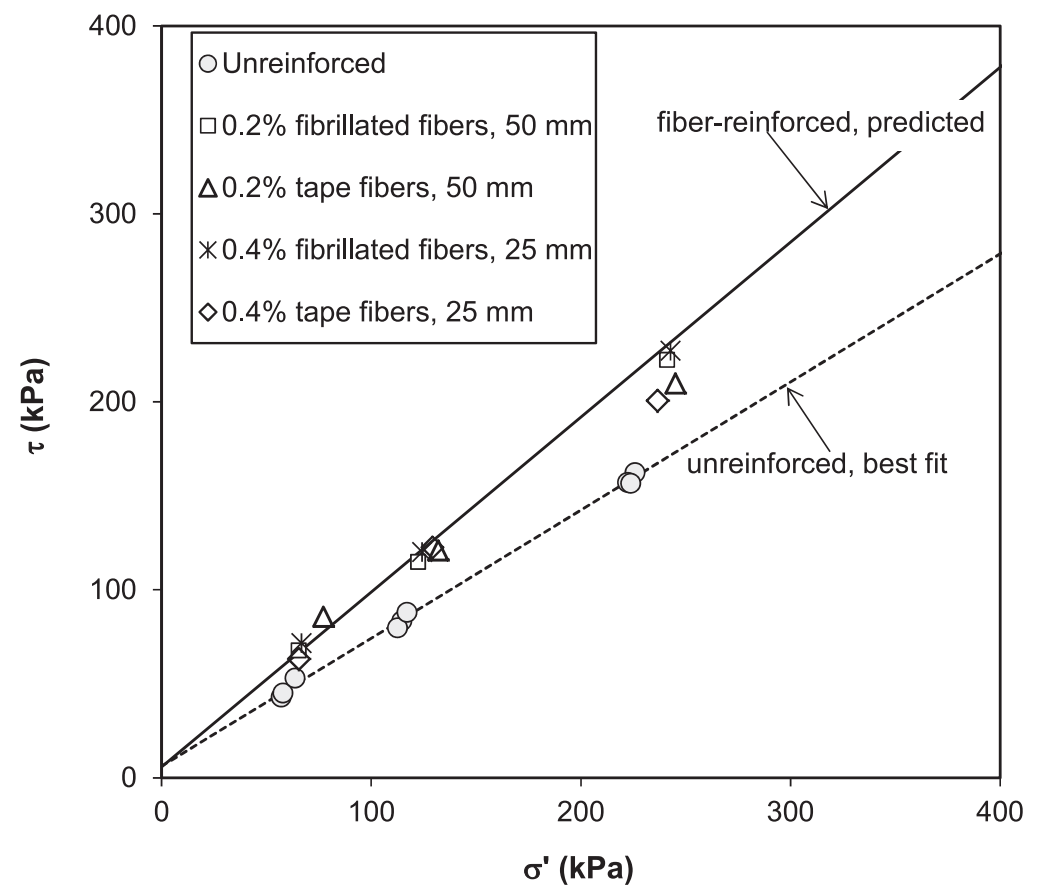

Fig. 5. Consolidated shear strength results for a specimen reinforced with 50-mm-long fibers (1,000 denier) placed at $\chi_{w}=0.2 \%$ and 25 -mm fibers placed at $\chi_{w}=0.4 \%$ (Soil 1)

\section{Stress-Strain Behavior of Fiber-Reinforced Soil}

\section{Effect of Fiber Content}

Fig. 7 shows the stress-strain behavior of specimens prepared at using a wide range of fiber content values (Test Series 2). The specimens were compacted to a relative density of $65 \%$. A more ductile behavior (i.e., smaller postpeak shear strength loss) was observed in the specimens prepared at comparatively higher fiber content, which was consistent with the results reported by other researchers (e.g., Maher and Gray 1990; Michalowski and Zhao 1996; Zornberg 2002). Even though the shear strength was observed to increase with increasing fiber content values, the initial portions of the stress-strain curves of the reinforced and unreinforced specimens were strikingly similar. 


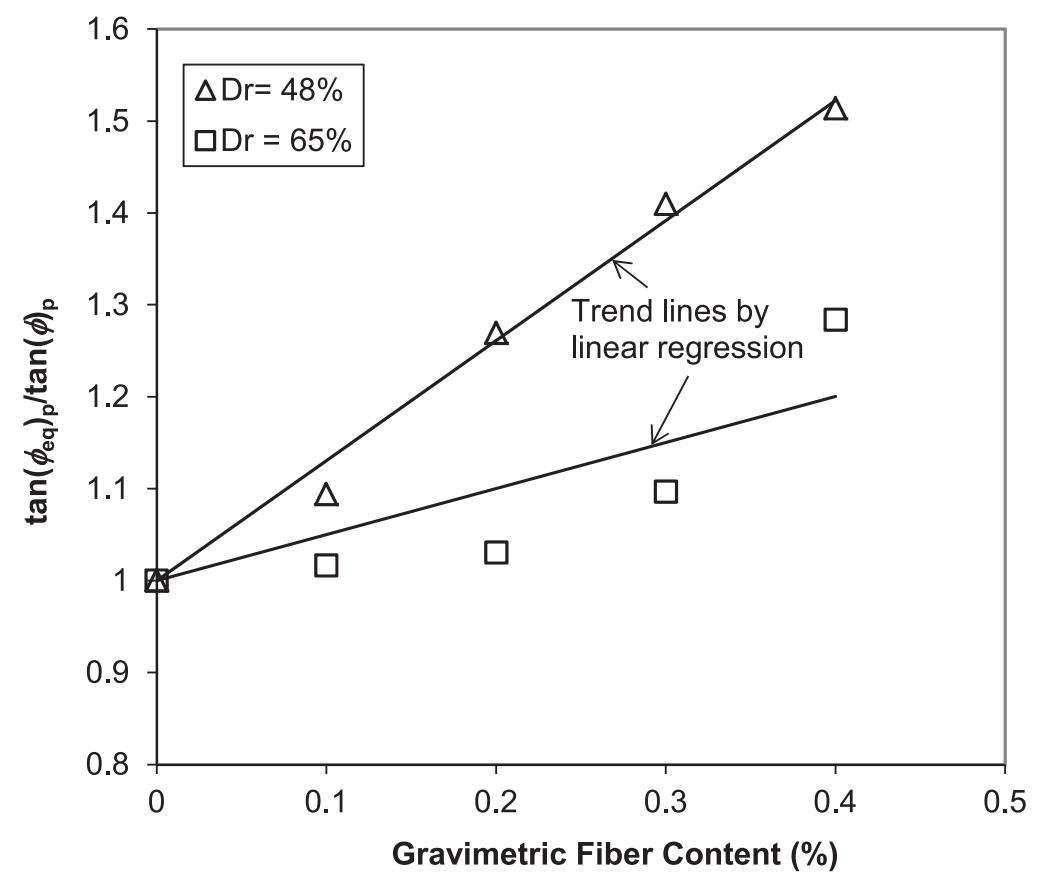

Fig. 6. Normalized friction angle as a function of fiber content (Soil 2)

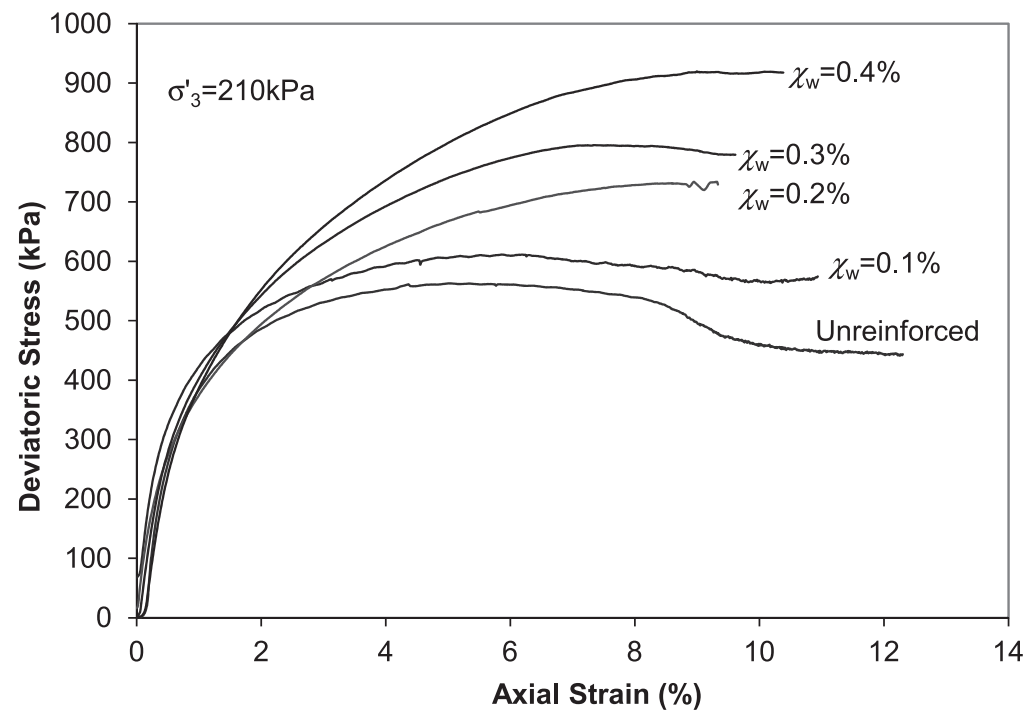

Fig. 7. Effect of fiber content on the stress-strain relationship (Soil $2, D_{r}=65 \%, \sigma_{3}=210 \mathrm{kPa}$ )

Accordingly, the soil matrix appeared to resist most of the applied load at small strain levels (without tensile contribution by the fibers), while the contribution of the fibers to the shear strength was mobilized at higher strain levels. For specimens prepared with varying fiber content values, the strain at peak strength was observed to increase with increasing fiber content. In unreinforced soil specimens, the strain at peak strength was about $5 \%$, while in the specimens prepared with $\chi_{w}=0.4 \%$, the maximum strength was reached at strain levels of approximately $10 \%$. This observation suggests that mobilization of the fiber-induced tension requires comparatively high shear strain values.

\section{Effect of Fiber Length}

The effect of fiber length on the stress-strain behavior of fiberreinforced specimens is shown in Fig. 8. The specimens were prepared using Soil 1 and 1,000-denier fibers. The specimens were prepared using the same gravimetric fiber content but with varying fiber lengths. The specimens reinforced with longer (50-mm) fibers displayed higher shear strength. The peak deviator stress increased linearly with increasing aspect ratio, which was consistent with the trend inferred from Eq. (2). The strain corresponding to the peak strength increased with increasing fiber length. When the governing failure mode was pullout, the fiberinduced distributed tension reached its peak when the pullout resistance was fully mobilized. Longer fibers required larger interface shear deformations to fully mobilize the interface strength. Consequently, the macroscopic axial strain at peak stress was expected to increase for specimens reinforced with longer fibers. 


\section{Effect of Soil Density}

The effect of soil density on the behavior of fiber-reinforced soil was evaluated to assess the mobilization of tension within fibers as a function of the strain level. In Test Series 2, the fiber-reinforced specimens were compacted to two different relative densities (48 and $65 \%$ ) for triaxial compression testing. A comparison between the effect of the soil densities on the fiber-reinforced and unreinforced soil specimens provides insight into of the progressive mobilization of fiber tension.

The results presented in Fig. 9 indicate that the unreinforced soil shows only a slight postpeak shear strength loss at a relative density of $48 \%$. On the other hand, the postpeak shear strength loss at a relative density of $65 \%$ is relatively pronounced. Shear stresses at large strain levels seem to converge to the same residual shear strength value, although equipment limitations did not allow for the specimens to be tested to their critical state.

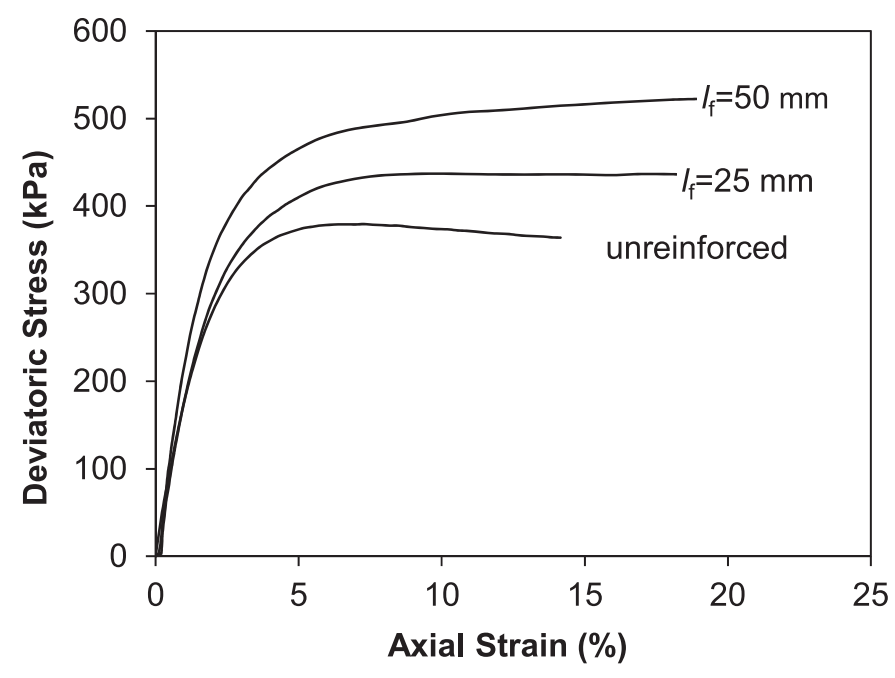

Fig. 8. Stress-strain behavior of specimens prepared using $\chi_{w}=0.2 \%$, with $l_{f}=25$ - and 50-mm, 1,000-denier fibers (Soil 1)
Fig. 10 compares the stress-strain behavior of fiber-reinforced soil specimens prepared using two relative densities $\left(D_{r}=48\right.$ and $65 \%)$ and three fiber contents $\left(\chi_{w}=0,0.1\right.$, and $\left.0.4 \%\right)$. Table 4 summarizes the peak and residual friction angle values. As shown in Fig. 10, the deviatoric stress of the tests conducted on specimens prepared using the same fiber content but with various soil densities seem to converge at large strain levels. The residual friction angles shown in Table 4 also appear to be independent of soil density, which is consistent with the response of unreinforced soil at large shear strain levels. These results are consistent with the fact that the two components of the equivalent shear strength envelope ( $S$ and $t$ ) are independent of the initial soil density. The fiber-induced tension, $t$, predicted using Eq. (2) is a function of the friction angle of the soil matrix. At large strain levels, because the residual shear strength of the soil matrix becomes independent of the initial soil density, $t$ also becomes independent of the initial density.

As shown in Fig. 10 and Table 4, increasing soil density leads to an increase in peak shear strength for low fiber contents (e.g., $0.1 \%$ fiber content in this study). This is because the peak strength is achieved at comparatively low shear strain levels when low fiber content is used. At low strain levels the shear strength of the soil matrix is governed by its density. When the fiber content is comparatively high (e.g., $0.4 \%$ fiber content in this study), the maximum shear strength is reached at comparatively high strain levels and the peak shear strength of the fiber-reinforced specimen is observed to be the same as the residual shear strength. Even though increasing soil density does not help increase the shear strength for comparatively high fiber contents, specimens compacted to higher density achieve high deviatoric stresses at comparatively low strain levels (see the results in Fig. 10 for the specimens prepared with $0.4 \%$ fiber content but compacted to various soil densities). Therefore, using high soil density may still be beneficial for limiting deformations in geotechnical projects.

\section{Selection of the Peak or Residual Strength of Unreinforced Soil for the Discrete Framework}

The stress-strain behavior of fiber-reinforced soil shown in the previous section suggests that the mobilization of fiber-induced

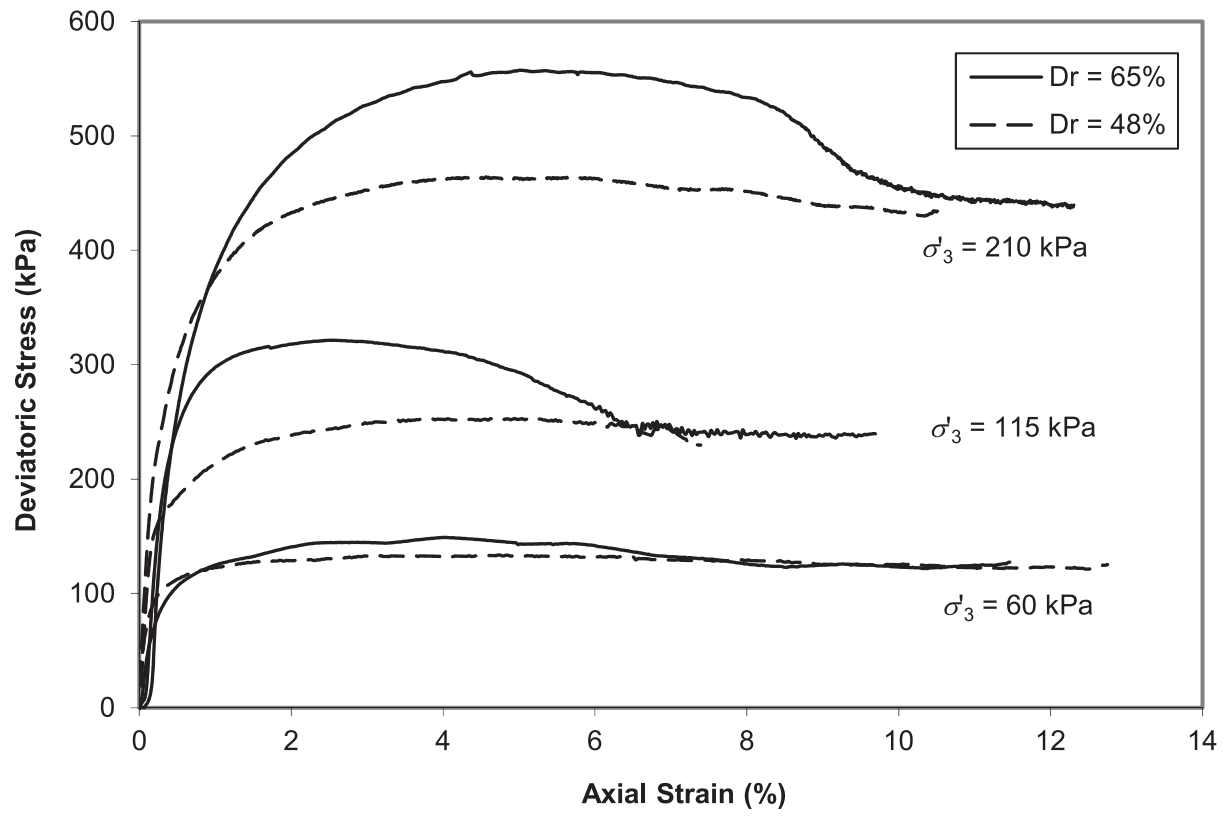

Fig. 9. Stress-strain behavior of unreinforced Soil 2 


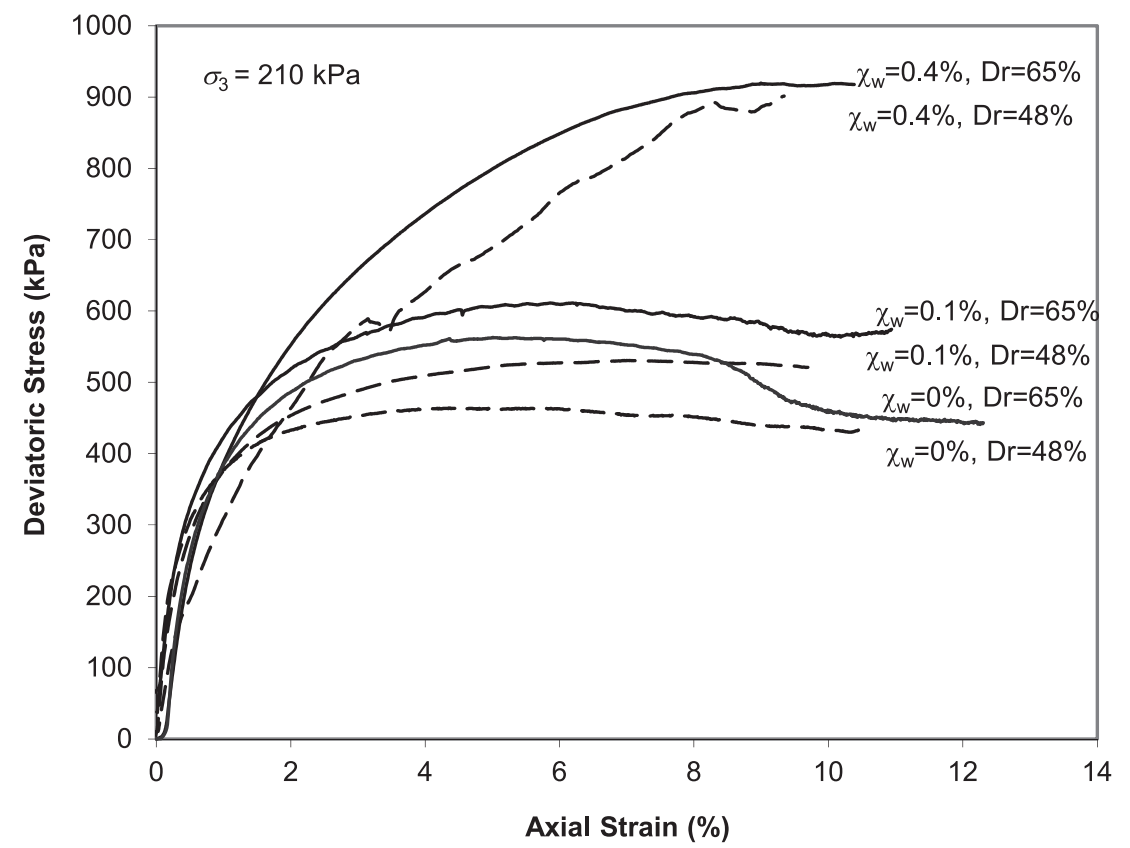

Fig. 10. Stress-strain curve of fiber-reinforced specimens compacted to various soil densities (Soil $2, \chi_{w}=0,0.1$, and $0.4 \%, \sigma_{3}=210 \mathrm{kPa}$ )

Table 4. Comparison of the Residual and Peak Friction Angles of Specimens Compacted to Two Different Densities

\begin{tabular}{lccccc}
\hline \multirow{2}{*}{$\begin{array}{l}\text { Gravimetric } \\
\text { fiber content }(\%)\end{array}$} & \multicolumn{2}{c}{ Peak friction angle } & & \multicolumn{2}{c}{ Residual friction angle } \\
\cline { 2 - 3 } \cline { 6 - 6 } & $D_{r}=48 \%$ & $D_{r}=65 \%$ & & $D_{r}=48 \%$ & $D_{r}=65 \%$ \\
\hline 0 & 31.6 & 35.2 & & 30.9 & 30.9 \\
0.1 & 32.8 & 36.3 & & 32.5 & 34.4 \\
0.2 & 38.1 & 39.1 & & 38.0 & 38.6 \\
0.3 & 41.2 & 42.1 & & 40.7 & 41.6 \\
0.4 & 43.2 & 43.5 & & 43.2 & 43.1 \\
\hline
\end{tabular}

Note: The peak and residual friction angles were obtained from linear regression of tests results for confining pressures of 60,115 , and $210 \mathrm{kPa}$.

tension requires a strain level higher than that required to mobilize the peak shear strength of unreinforced soil. Consequently, selection of the peak or residual strength of unreinforced soil for prediction of the equivalent shear strength of fiber-reinforced soil requires establishing strain compatibility considerations. This is particularly relevant for dense soils, which display a comparatively large difference between their peak and residual shear strength values.

Conceptually, the use of the peak or residual shear strength of unreinforced soil in the discrete framework should be determined considering the strain at peak strength for the fiber-reinforced and unreinforced soils. If the strain level $\left(\varepsilon_{m, r}\right)$ at which the shear strength of fiber-reinforced soil is mobilized is comparatively higher than the strain at the peak shear strength of unreinforced soil $\left(\varepsilon_{m}\right)$, the residual shear strength (rather than the peak shear strength) of the soil matrix will define the contribution of the soil matrix to the equivalent shear strength of the fiber-reinforced soil.

As discussed in the previous section, $\varepsilon_{m, r}$ is a function of the fiber content. Fiber-reinforced soils may or may not show postpeak shear strength loss depending on the fiber content. To predict the equivalent shear strength of fiber-reinforced soil accounting for the differences in the responses between comparatively high and low fiber contents, a factor to account for partial mobilization of ultimate fiber tension is proposed herein. Considering an unreinforced soil with peak shear strength parameters $\phi$ and $c$, and residual shear

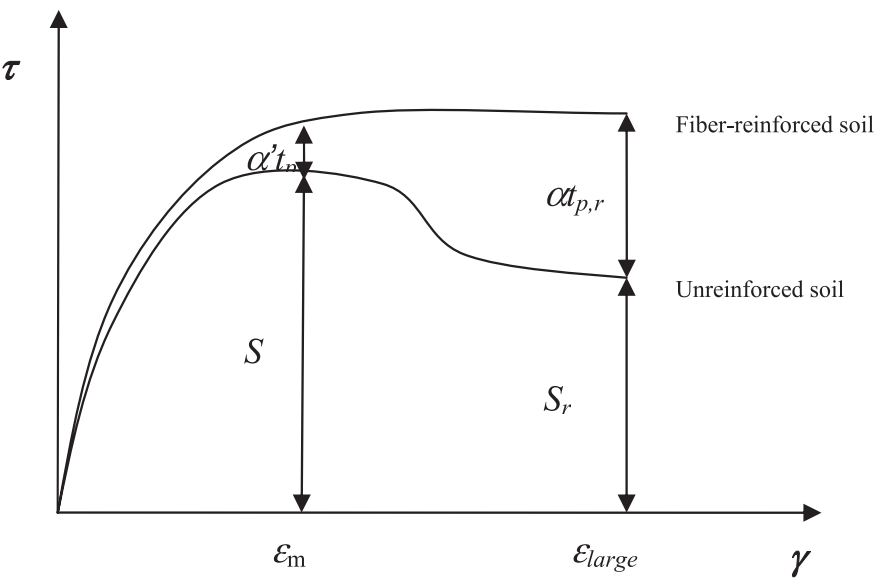

Fig. 11. Shear strength components of fiber-reinforced soil at various strain levels

strength parameters $\phi_{r}$ and $c_{r}$, the two components of the equivalent shear strength ( $S$ and $t)$ at two strain levels (peak and residual), can be calculated as given in the subsequent sections (see Fig. 11).

\section{At the Strain Level Where the Peak Shear Strength of the Soil Matrix Is Mobilized}

The contribution of the soil matrix is

$$
S=c+\sigma_{n} \tan \phi
$$

Because the fiber-induced tension is not fully mobilized at this strain level, the contribution of the fibers is proposed to be calculated as

$$
\bar{\alpha} \alpha t_{p}=\bar{\alpha} \alpha \chi \cdot \eta \cdot\left(c_{i, c} \cdot c+c_{i, \phi} \cdot \tan \phi \cdot \sigma_{n, \text { ave }}\right)
$$

In this case, $\alpha=$ factor that accounts for the fiber orientation and $\bar{\alpha}=$ new factor that accounts for the partial mobilization of fiber-induced 
tension mobilized at this strain level. Factor $\bar{\alpha}$ is influenced by the bonding between the fiber and soil. A good bonding is expected to minimize the relative displacement between the fiber and soil that is required to mobilize the interface shear strength; consequently, $t_{p}$ can be mobilized at comparatively low strain levels. For the polypropylene fibers and uniform sand used in this study, backcalculation of test results indicated that approximately $60-70 \%$ of $t_{p}$ was mobilized at this strain level (i.e., $\left.\bar{\alpha}=0.6-0.7\right)$. Here, $\alpha$ and $\bar{\alpha}$ can be combined into a new factor, $\alpha^{\prime}\left(\alpha^{\prime}=\alpha \alpha^{\prime}\right)$. The shear strength of fiber-reinforced soil mobilized at this strain level, $S_{\mathrm{eq}, 1}$, can be calculated as

$$
S_{\mathrm{eq}, 1}=S+\alpha^{\prime} \cdot t_{p}
$$

\section{At the Strain Level Where the Residual Shear Strength of the Soil Matrix Is Fully Mobilized}

The contribution of the soil matrix is

$$
S_{r}=c_{r}+\sigma_{n} \tan \phi_{r}
$$

The fiber-induced tension is fully mobilized at this strain level (i.e., $\bar{\alpha}=1.0$ ) and the contribution of the fiber-induced tension is

$$
\alpha t_{p, r}=\alpha \chi \cdot \eta \cdot\left(c_{i, c} \cdot c_{r}+c_{i, \phi} \cdot \tan \phi_{r} \cdot \sigma_{n, \text { ave }}\right)
$$

where $t_{p, r}=$ fiber-induced tension at a large strain level.

The shear strength at a large strain level, $S_{\text {eq }, 2}$, can be calculated by

$$
S_{\mathrm{eq}, 2}=S_{r}+\alpha \cdot t_{p, r}
$$

Ultimately, the actual (i.e., maximum) shear strength of fiberreinforced soil $S_{\text {eq }}$ can be determined by

$$
S_{\mathrm{eq}}=\max \left(S_{\mathrm{eq}, 1}, S_{\mathrm{eq}, 2}\right)
$$

For dense soils reinforced using a relatively low fiber content, $S_{\mathrm{eq}, 1}$ is typically greater than $S_{\mathrm{eq}, 2}$, and the shear strength of the fiberreinforced soil is governed by the peak shear strength of soil matrix. Postpeak shear strength loss is expected in fiber-reinforced soil specimens prepared with comparatively low fiber content values.

For dense soils reinforced using a comparatively high fiber content,

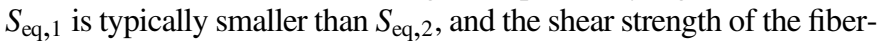
reinforced soil is governed by the residual shear strength of the soil matrix. The soil density is not expected to influence the shear strength and no postpeak shear strength loss is expected in fiber-reinforced soil specimens prepared with comparatively high fiber content values.

\section{Conclusions}

Evaluation of the stress-strain response of fiber-reinforced soils prepared with various fiber contents and soil densities was presented in this paper. Based on these results, a refinement of the discrete framework for prediction of the equivalent shear strength of fiber-reinforced soil (Zornberg 2002) is proposed to account for the compatibility of strains at which the shear strength of the soil and the fiber-induced tensions are fully mobilized. The following conclusions can be drawn from this evaluation:

1. Full mobilization of fiber-induced tension requires comparatively high strain levels.

2. For soils prepared with comparatively high fiber contents, the initial density of the soil does not significantly influence the shear strength of the fiber-reinforced soil. The residual shear strength of the unreinforced soil should be used to predict the equivalent shear strength of fiber-reinforced soil using the discrete framework.

3. For soils prepared with comparatively low fiber content and conditions where the unreinforced soil stress-strain response shows a postpeak shear strength loss, the peak shear strength of the unreinforced soil should be used to predict the equivalent shear strength of the fiber-reinforced soil using the discrete framework.

Use of the peak or residual shear strength of the soil matrix in the discrete framework can be defined by calculating the equivalent shear strength twice; i.e., at strain levels corresponding to both the peak and residual shear strength of the soil matrix. The equivalent shear strength of the fiber-reinforced soil corresponds to the maximum of these two values.

\section{References}

ASTM. (1995). "Standard test method for consolidated undrained triaxial compression test for cohesive soils." ASTM D4767-11, West Conshohocken, PA.

ASTM. (1997). "Standard test method for tensile properties of yarns by the single-strand method." ASTM D2256-97, West Conshohocken, PA.

Juran, I., and Chen, C. L. (1988). "Soil-geotextile pull-out interaction properties: testing and interpretation." Transportation Research Record 1188, Transportation Research Board, Washington, DC, 37-47.

Li, C., and Zornberg, J. G. (2003). "Validation of discrete framework for fiber-reinforcement." Proc., North American Conf. on Geosynthetics, North American Geosynthetics Society, Albany, NY.

Maher, M. H., and Gray, D. H. (1990). "Static response of sand reinforced with randomly distributed fibers." J. Geotech. Eng., 116(11), 16611677.

Michalowski, R. L., and Cermark, J. (2003). “Triaxial compression of sand reinforced with fibers." J. Geotech. Geoenviron. Eng., 129(2), 125136.

Michalowski, R. L., and Zhao, A. G. (1996). "Failure of fiber-reinforced granular soils." J. Geotech. Engrg., 122(3), 226-234.

Sadek, S., Najjar, S. S., and Freiha, F. (2010). "Shear strength of fiberreinforced sands." J. Geotech. Geoenviron. Eng., 136(3), 490-499.

Zornberg, J. G. (2002). "Discrete framework for limit equilibrium analysis of fibre-reinforced soil." Geotechnique, 52(8), 593-604.

Zornberg, J. G., and Li, C. (2003). "Design of fiber-reinforced soil." Proc., 12th Panamerican Conf. of Soil Mechanics and Geotechnical Engineering, Cambridge, MA, Vol. 2, 2193-2200.

Zornberg, J. G., Somasundaram, S., and LaFountain, L. (2001). "Design of geosynthetic-reinforced veneer slopes." Proc., Int. Symp. on Earth Reinforcement (IS Kyushu 2001), H. Ochiai, J. Otani, N. Yasufuku, and K. Omine, eds., Vol. 1, Balkema, Tokyo, 305-310. 